\title{
APPLICATION OF THE ANTIBIOTIC DISK DIFFUSION METHOD TO MULTIVARIATE PROFILING OF SOIL BACTERIAL COMMUNITY: COMPARING THE POWER TO DISCRIMINATE DIFFERENT SOILS AND DIMENSION OF THE DISCRIMINATION WITH THAT OF THE BIOLOG METHOD
}

\author{
Ryoichi Doi* \\ Seisan-Kankyou (NPO), 369/130 M2, Bangmod, Rattburana, Bangkok 10140, Thailand \\ Submitted: July 22, 2003; Approved: October 21, 2003
}

\begin{abstract}
The antibiotic disk diffution (ADD) method was compared with the Biolog method in terms of power to discriminate soils and dimension of the discrimination. Soils from a forest and a citrus field in Thailand were profiled with these methods. These methods differentiated the soils in the principal component score plots. Then, Wilk's lambda statistic was determined to estimate power of these methods to discriminate the soils. The ADD method scored Wilk's lambda of $0.003(\mathrm{p}=0.144)$ and $0.000(\mathrm{p}=0.020)$, for direct and ratio-transformed calculation, respectively. The Biolog method recorded Wilk's lambda of $0.001(\mathrm{p}=0.067), 0.003(\mathrm{p}=0.144)$ and 0.035 ( $\mathrm{p}=0.440$ ), at $0.25,0.50$ and 0.75 average well color developments (AWCDs), respectively. The ADD method showed high discrimination power, or at least comparable to that of the Biolog method. Redundancy analysis (RDA) resulted in ordination diagrams, which revealed a difference in dimension of the soil discrimination among the methods and the AWCDs. The soil environmental factors significantly related to the bacterial profiles at $\mathrm{p}=0.05$ were: available phosphorus (ADD method and Biolog $0.25 \mathrm{AWCD}$ ), and $\mathrm{pH}$ (Biolog 0.50 and $0.75 \mathrm{AWCD}$ ). These results indicated that the profiling methods and the AWCDs revealed the multidimensionality of the discrimination. The possibility of the application of the ADD method to extraction of such pieces of information for effective land management was suggested.
\end{abstract}

Key words: antibiotic, Biolog, disk diffusion, soil microbial community.

\section{INTRODUCTION}

Changes in soil quality have many aspects, physical, chemical and biological ones (20). The biotic profile of soil may be used as an indicator of soil health (21). Thus, to analyze a biotic profile of soil is expected to help more efficient management of the land. In terms of soil biotic profiling, multivariate methods are thought to be more informative in comparison with methods that give single variables (23). Analyzing a multivariate data set on soil, we often find dimensions relating important soil-relating facts (23). For example, principal component (PC) analysis extracts such dimensions in relation to soil quality, then finds PCs as integrated measures of productivity (e.g., 19) or problem (e.g., 9).
There are several multivariate methods to biologically profile soils such as the phospholipid fatty acid analysis (25), respiratory quinone profiling (10) or the Biolog method (11). Bossio and Scow (3) analyzed relations between Biolog profiles and soil environmental factors over differently managed lands, then found significant soil environmental factors related to the Biolog profiles. Such a strategy is expected to provide useful information that helps efficient land management practices.

Several multivariate methods to biologically profile soils require heavy investment, well-trained workers or suitable socioeconomic environments. This research aimed to examine a method using antibiotics, which is free from the requirements listed above. The method was tested as a variation of the antibiotic-involving approach reported by Brønstad et al. (4)

*Corresponding author: Mailing Address. Seisan-Kankyou (NPO), 369/130 M2, Bangmod, Rattburana, Bangkok 10140, Thailand. Tel: (+662) 8706401. Fax: (+662) 870-6401 to 6420 ext. 130. E-mail address: skrt@doramail.com 
and Doyle and Stotzky (6), who profiled soil bacterial communities based on resistance pattern of each isolate to a variety of antibiotics. The susceptibility of soil bacterial community to antibiotics had been thought to be determined by directly exposing the community to a variety of antibiotics. The disk diffusion method is used to measure susceptibility of a microbe to an antibiotic (1). The method is usually used to test an isolate. Though soil microbial communities are complex, there still had been the possibility that the disk diffusion method profiles soil microbial communities in a multivariate manner. An agar plate may allow only a small portion of a soil microbial community to grow (13). This selectivity was expected to contribute to the formation of a clear arc around a disk on the agar plate.

The first objective of this research was to profile soils with the Antibiotic Disk Diffusion (ADD) method. Soils sampled at a forest and a citrus field were profiled with the ADD method, and the profiles were used to determine Wilk's lambda, which is a statistic that indicates discrimination power of the ADD method. Then, the discrimination power was compared with that of the Biolog method (11), which is widely used in profiling microbial communities in various environments.

The second objective of this research was to compare the most significant dimensions of the soil discrimination between the profiling methods. The ADD method was compared with the Biolog method (11) at different average well color developments (AWCDs). The multidimensionality of difference in soil quality has been implied $(15,18,22)$. Each dimension may be differently important as revealed by principal component analysis of a multivariate data set $(23,26)$. Relationships between soil environmental factors and soil-relating biotic profiles given by different profiling methods also have implied diverse dimensions $(15,18,22)$. Thus, the profiles obtained with the ADD and the Biolog methods were analyzed by redundancy analysis to define the most significant dimension of the soil discrimination for each method.

\section{MATERIALS AND METHODS}

\section{Soil samples}

Two soils were collected at a dry evergreen forest (DEF) and a citrus field (CF), both in Thailand. These soils were profiled to score and compare discrimination power of the two methods and to compare dimensions of the discrimination. The DEF is located in the Sakaerat Environmental Research Station (SERS), Nakon Rachasima province, Thailand. The forest is primarily dominated by Hopea ferrea. and Shorea spp. (16). The soil is classified as an Orthic Acrisol (8). The SERS receives most of the annual precipitation during the rainy season, May to October (5). The soil was sampled on June 11, 2001. In the DEF, a sampling plot, $10 \mathrm{~m}$ in diameter, was set. Soil sampling was done at 6 points randomly selected in the circle. At each sampling point, 2 soil cores, apart $1 \mathrm{~m}$ each other, were sampled. A hundred $\mathrm{mL}$ core samplers, $5 \mathrm{~cm}$ in diameter, were inserted from the surface into $5.1 \mathrm{~cm}$ depth. 2 core samples at a point were immediately mixed to make a composite. The 6 composites were air-dried at room temperature in the dark for a month, passed $2 \mathrm{~mm}$ screen, then kept in plastic bags at room temperature. The CF is located in Bangkok, Thailand. It has been managed as a CF for more than 15 years. The soil is classified as an Eutric Gleysol (8). The soil was sampled on May 15, 2001. The citrus trees were planted on ridges surrounded by watercourses. A ridge $3 \mathrm{~m}$ in width and $25 \mathrm{~m}$ in length was chosen. Three sampling points were set along each longer side of the ridge, around the midpoint. Along the side, each sampling point was $5 \mathrm{~m}$ apart from the nearest one. 2 cores, $1 \mathrm{~m}$ apart each other along the side, were sampled at a sampling point and immediately mixed as a composite. The 6 composites were air-dried and kept as in the case of the DEF soil.

\section{Antibiotic disc diffusion method}

Each soil sample was profiled with two replications. The basal medium was prepared to give final concentrations of $1 \mathrm{~g}$ $\mathrm{K}_{2} \mathrm{HPO}_{4}, 0.5 \mathrm{~g} \mathrm{KNO}_{3}, 0.2 \mathrm{~g} \mathrm{MgSO}_{4} \cdot 7 \mathrm{H}_{2} \mathrm{O}, 0.1 \mathrm{~g} \mathrm{CaCl}_{2}, 0.1 \mathrm{~g} \mathrm{NaCl}$, $2 \mathrm{mg} \mathrm{FeCl}_{3}$ and $1 \mathrm{~g}$ glucose/L. The number of colonies of bacteria from the DEF soil that appeared on this medium was comparable to that on the medium to culture oligotrophic bacteria developed by Angle et al. (2). The $\mathrm{pH}$ was adjusted to 6.0. Agar was added to the basal medium at $1.5 \%(\mathrm{w} / \mathrm{v})$, autoclaved at $120^{\circ} \mathrm{C}$ for 15 min and cooled to $55^{\circ} \mathrm{C}$. Tetrazolium violet and cycloheximide were filter sterilized $(0.20 \mu \mathrm{m}$, Toyo Roshi Kaisha, Ltd., Japan) and added to the cooled agar medium at final concentrations of $0.01 \%(\mathrm{w} / \mathrm{v})$ for each. Cycloheximide was added as a fungicide. Tetrazolium violet was added to help observation of purple color development that indicates physiological activity of the inoculated microbial community on the agar plate. If the concentration of the antibiotic is high enough to inhibit the physiological activity of the microbes, the color development does not occur around the paper disk. A preliminary test generated no visible inhibitory zones without addition of tetrazolium violet. Twenty $\mathrm{mL}$ of this medium was poured into a petri dish ( $87 \mathrm{~mm}$ in diameter) and solidified at room temperature. Fifteen $\mathrm{g}$ of the air-dried sample was suspended in exactly 5 volumes of sterilized water and reciprocally shaken at room temperature for $30 \mathrm{~min}$ at $120 \mathrm{rpm}$. After $15 \mathrm{~s}, 60 \mathrm{~mL}$ of the upper phase was decanted and centrifuged at $1,000 \mathrm{~g}$ for $10 \mathrm{~min}$ at $25^{\circ} \mathrm{C}$. The supernatant was discarded and the pellet was resuspended in $3 \mathrm{~mL}$ of sterilized water. $1 \mathrm{~mL}$ of the suspension was poured onto the agar plate and spread. Air was aseptically supplemented to expel excessive moisture on the agar plate. The concentrations of the antibiotic solutions were: ampicillin (in $25 \%$ ammonium hydroxide at $20 \mathrm{gL}^{-1}$, then the $\mathrm{pH}$ was adjusted to 6.0); chloramphenicol (in 50\% ethanol at $50 \mathrm{gL}^{-1}$ ); dapson (in 50\% ethanol at $16 \mathrm{gL}^{-1}$ ); erythromycin (in 50\% ethanol 
at $50 \mathrm{gL}^{-1}$ ); kanamycin sulfate (in water at $50 \mathrm{gL}^{-1}$ ); lasalocid (in $50 \%$ ethanol at $5 \mathrm{gL}^{-1}$ ); nafcillin (in 50\% ethanol at $100 \mathrm{gL}^{-1}$ ); nalidixic acid (in $50 \%$ ethanol at $2 \mathrm{gL}^{-1}$ ); neomycin $\bullet \mathrm{HCl}$ (in water at $40 \mathrm{gL}^{-1}$ ); novobiocin (in water at $40 \mathrm{gL}^{-1}$ ); penicillin $\mathrm{G}$ (in water at $100 \mathrm{gL}^{-1}$ ); spectinomycin॰2 $\mathrm{HCl}$ (in water at $100 \mathrm{gL}^{-1}$ ); streptomycin sulfate (in water at $200 \mathrm{gL}^{-1}$ ); sulfamethoxazole (in water at $10 \mathrm{gL}^{-1}$ ); tetracycline (in water at $80 \mathrm{gL}^{-1}$ ); and trimethoprim (in 50\% ethanol at $20 \mathrm{gL}^{-1}$ ). These antibacterials were selected to profile the soils based on susceptibility patterns of the bacterial communities (1). Paper disks $6 \mathrm{~mm}$ in diameter were prepared from Whatman No. 2 filter paper and autoclaved. Four $\mu \mathrm{L}$ of the filter sterilized antibiotic solution was loaded onto a disk. In addition to the 16 antibiotics above, disks loaded with $4 \mu \mathrm{L}$ of both the streptomycin and sulfamethoxazole solutions or with $4 \mu \mathrm{L}$ of both the tetracycline and trimethoprim solutions were prepared. The disks were air-dried for $30 \mathrm{~min}$ at room temperature, put onto the plates at 6 disks/plate. The agar plates were incubated at $28^{\circ} \mathrm{C}$ in the dark for $30 \mathrm{~h}$, then the distances between disk and inhibitory zone edge were measured. The occurrence or the inhibition of the color development was observed from the bottom of the petri dish. Ampicillin and streptomycin on some plates generated duplicated circles around a disk, the outer inhibitory zone was slightly colored. In such a case, the larger circle was measured. A preliminary experiment was made to profile a soil from a laurel forest in Japan with the ADD method, and the average of coefficient of variance among the ADD variables above was $0.043(n=2)$.

\section{Biolog method}

Each soil smaple was profiled with two replications. $5 \mathrm{~g}$ of each soil sample was suspended in exactly 9 vol of sterilized water, reciprocally shaken at room temperature for $30 \mathrm{~min}$ at $120 \mathrm{rpm}$. Then, the suspension was centrifuged at $1,000 \mathrm{~g}$ for $10 \mathrm{~min}$, and the pellet was suspended in $45 \mathrm{~mL}$ of sterilized water. The soil suspension was diluted 20 times with sterilized water. The diluted suspension was added to Biolog Gram Negative (GN) plate at a rate of $0.1 \mathrm{~mL} /$ well. The plates were incubated at $28^{\circ} \mathrm{C}$ in the dark and absorbance at $405 \mathrm{~nm}$ was read at 8 to $24 \mathrm{~h}$ intervals for 8 days using an ELISA plate reader (Model 550, Bio-Rad, California). During the incubation, the plates were wrapped in a plastic film to avoid desiccation. The Average Well Color Development (AWCD) method proposed by Garland and Mills (11) was used for analyses of the Biolog data. AWCD at a particular time was calculated using the following equation.

\section{$\mathrm{AWCD} t=\Sigma(\mathrm{ABSit}-\mathrm{ABSrt}) / 95$}

where ABSit is absorbance at $405 \mathrm{~nm}$ for the $i$-th carbon source at the time $(t)$ and ABSrt is that for the control well having no carbon sources. The AWCDs for the soil samples converged to around 0.9 during the incubation period. Negative values given by equation 1 were regarded as 0 , and this resulted in an increase in the AWCD at a negligible rate of less than 3\%.

\section{Determination of soil properties}

The soil samples were suspended in water at a soil to solution ratio of 1:5 and reciprocally shaken at room temperature for $1 \mathrm{~h}$ at $120 \mathrm{rpm}$ to determine their $\mathrm{pHs}$ and electrical conductivities (ECs). Total C (TC) and $\mathrm{N}(\mathrm{TN})$ in the soils were determined using an NC analyzer (Sumigraph model NC-80, Sumitomo Kagaku Kogyo, Japan). Available phosphorus was determined with the Bray II method.

\section{Statistical analyses}

The independent sample t-test was performed to test the significant difference between means using the statistical software, SPSS 10.0.5J (SPSS Japan Inc., Tokyo). To compare discrimination power of the methods, Wilk's lambda and its significance were also determined with SPSS 10.0.5J. In this research, the distinctiveness of differences between the two soils recognized by each method or at each AWCD value was regarded as the discrimination power. Wilk's lambda is a widely used statistic, which indicates the degree of similarity between multivariate data sets (28). Wilk's lambda ranges from 0 to 1 . The more different the data sets are, the closer Wilk's lambda converges to 0 . Thus, when a method scores a small value of Wilk's lambda, it means that the method well discriminates the soils. To determine Wilk's lambda, data for the ADD method were directly used or ratio-transformed to standardize the row data. In this standardization, each observation was divided by the sum of the 18 observations for the soil sample, and used for the calculation. Wilk's lambda for the Biolog method was determined at AWCD values of $0.25,0.50$ and 0.75 . Lindstrom $e t$ al. (17) pointed out that rapidly and slowly metabolized carbon sources may differently contribute to discrimination of soil microbial communities. Depending on AWCD values, such differential rates of utilization might result in success or failure in soil discrimination. To investigate this possibility, absorbance values for each carbon source at the AWCD values above were used for statistical analyses.

Principal Component Analysis (PCA) to elucidate the pattern of variation of soil bacterial community profile was also performed using the SPSS software. For the ADD data set, the ratio-transformed values were used for PCA. Redundancy analysis (RDA) and summarizing the result as an RDA ordination diagram were performed using CANOCO for Windows 4.02 and CanoDraw 3.10 (Microcomputer Power, NY, each), respectively. RDA is a multivariate statistical technique to relate species distribution patterns and environmental factors in decreased dimensionality. Hence, this kind of statistical technique is categorized as the direct gradient analysis. RDA specifies statistically more/less significant environmental factors as gradients in relation to species distribution patterns. RDA 
detects linear species distribution patterns against an environmental gradient (24). The significant environmental gradients are shown as vectors from the origin of the ordination diagram. Thus, in this paper, significant environmental gradients and some bacterial variables have linear correlations. In the same diagram, the soil samples are located according to their scores on the ordination axes. To test the significance of the soil environmental factors, a Monte Carlo permutation test was done at 199 random permutations.

\section{RESULTS}

\section{Soil properties}

The soils were distinctively different in color, the CF soil was dark gray, while the DEF soil was light brown. The soils were also different in chemical characteristics (Table 1). According to the t-test, the $\mathrm{pH}$ and $\mathrm{EC}$ in the $\mathrm{CF}$ soil was higher. The CF soil was richer in TN, TC and available phosphorus. The DEF soil had a larger $\mathrm{C} / \mathrm{N}$ ratio.

\section{Differences in susceptibility pattern between the soils}

Susceptibility patterns of the microbial communities to the antibiotics are summarized (Table 2). On each agar plate, a purplecolored area surrounding inhibitory circles around the disks was seen. The boundary between the colored and the uncolored areas was clear. The bacterial community in the CF soil was more susceptible to ampicillin, chloramphenicol, erythromycin, nalidixic acid, penicillin $\mathrm{G}$, spectinomycin $2 \mathrm{HCl}$, streptomycin, sulfamethoxazole and the two antibiotic mixtures, while the DEF counterpart was more susceptible to dapson, neomycin $\bullet \mathrm{HCl}$ and novobiocin. The other treatments did not find significant differences in susceptibility between the soil microbial communities. Among the antibiotics, no synergetic or antagonistic effects that change the shape of the circle were observed. The statistical analysis concluded a distinctive difference between the susceptibility patterns of the soil bacterial communities (Table 3). The ADD method recorded low Wilk's lambda values and high significance. Discrimination power of the Biolog method gradually decreased as the color development was going on, scoring a larger Wilk's lambda value and lower significance. The ratio-transformation for the ADD method improved the discrimination power.
Table 2. Antibiotic susceptibility profiles of the air-dried soils.

\begin{tabular}{lrrr}
\hline \multirow{2}{*}{ Antibiotic(s) } & \multicolumn{2}{c}{ Management practices } & \\
\cline { 2 - 3 } & $\begin{array}{c}\text { Citrus } \\
\text { field }\end{array}$ & $\begin{array}{c}\text { Dry } \\
\text { evergreen } \\
\text { forest }\end{array}$ & Significance \\
\hline Ampicillin & $12.5(2.0) \dagger$ & $8.0(0.9)$ & $* *$ \\
Chloramphenicol & $9.7(1.2)$ & $1.3(0.8)$ & $* *$ \\
Dapson & $0.5(0.5)$ & $1.3(0.5)$ & $*$ \\
Erythromycin & $2.0(0.0)$ & $0.8(0.8)$ & $*$ \\
Kanamycin sulfate & $10.7(0.8)$ & $11.3(1.5)$ & NS \\
Lasalocid & $0.8(1.6)$ & $0.0(0.0)$ & NS \\
Nafcillin & $1.0(0.0)$ & $1.3(0.8)$ & NS \\
Nalidixic acid & $7.3(3.4)$ & $0.0(0.0)$ & $* *$ \\
Neomycin $\bullet H C l$ & $0.0(0.0)$ & $8.5(1.2)$ & $* *$ \\
Novobiocin & $4.2(4.7)$ & $9.2(1.5)$ & $*$ \\
Penicillin G & $5.8(2.9)$ & $2.0(0.6)$ & $*$ \\
Spectinomycin $\bullet 2 \mathrm{HCl}$ & $6.7(1.0)$ & $2.2(0.8)$ & $* *$ \\
Streptomycin & $7.8(3.0)$ & $1.8(1.0)$ & $* *$ \\
Sulfamethoxazole & $9.2(3.0)$ & $1.3(1.0)$ & $* *$ \\
Tetracycline & $0.2(0.4)$ & $0.2(0.4)$ & NS \\
Trimethoprim & $7.5(2.6)$ & $6.2(1.7)$ & NS \\
Streptomycin + & $6.8(3.0)$ & $1.3(1.0)$ & $* *$ \\
Sulfamethoxazole & & & \\
Tetracycline + & $3.7(0.8)$ & $0.2(0.4)$ & $* *$ \\
Trimethoprim & & & \\
\hline
\end{tabular}

$\dagger$ The values indicate distance between the antibiotic disk to arc of the inhibitory circle $(\mathrm{mm})$. The values in the parentheses are the standard deviations. *,** and NS indicate significant at $\mathrm{p}=0.05,0.01$ and not significant, respectively.

\section{Principal component analysis}

PCA of each data set on the bacterial communities resulted in a PC score plot in which the soil sample groups were separately located (Fig. 1). The ADD method gave a PC score plot separating the sample groups on the first PC axis (Fig. 1a). In the PC score plots for AWCD values of 0.25 and 0.50 in the Biolog method, the sample groups were separated by the second PC axis (Fig. $1 \mathrm{~b}$ and c). In the PC score plot for an AWCD value of 0.75 , the sample groups were separated by both the first and second PCs (Fig. 1d). The first axis for the ADD method explained the variation at the highest rate of $56 \%$ in comparison with the

Table 1. Characteristics of the soils.

\begin{tabular}{lcccccccc}
\hline $\begin{array}{c}\text { Management } \\
\text { practice }\end{array}$ & Province & $\begin{array}{c}\text { FAO/UNESCO } \\
\text { classification }\end{array}$ & $\mathrm{pH}$ & $\begin{array}{c}\mathrm{EC} \\
\left(\mathrm{mS} \mathrm{m}^{-1}\right)\end{array}$ & $\begin{array}{c}\text { Total C } \\
\left(\mu \mathrm{g} \mathrm{g}^{-1} \mathrm{dry} \text { soil }\right)\end{array}$ & $\begin{array}{c}\text { Total N } \\
\left(\mu \mathrm{g} \mathrm{g}^{-1} \text { dry soil }\right)\end{array}$ & $\mathrm{C} / \mathrm{N}$ & $\begin{array}{c}\text { Bray II P } \\
\left(\mu \mathrm{g} \mathrm{g}^{-1} \text { dry soil }\right)\end{array}$ \\
\hline $\begin{array}{l}\text { Citrus field } \\
\text { Dry evergreen } \\
\text { forest }\end{array}$ & $\begin{array}{c}\text { Bangkok } \\
\text { Nakon } \\
\text { Rachasima }\end{array}$ & Eutric Gleysol & $7.44^{\mathrm{a}}$ & $134^{\mathrm{a}}$ & $31.8^{\mathrm{a}}$ & $2.76^{\mathrm{a}}$ & $11.6^{\mathrm{a}}$ & $325^{\mathrm{a}}$ \\
Orthic Acrisol & $4.69^{\mathrm{b}}$ & $5.19^{\mathrm{b}}$ & $21.6^{\mathrm{b}}$ & $1.67^{\mathrm{b}}$ & $12.9^{\mathrm{b}}$ & $34.5^{\mathrm{b}}$ \\
\hline
\end{tabular}

*Figures in the same column indexed by the same letter are not significantly different at $\mathrm{p}=0.05$ according to the $\mathrm{t}$-test ( $\mathrm{n}=6$ for each soil). 
Table 3. Comparison of discrimination power of the tested methods.

\begin{tabular}{lccc}
\hline \multicolumn{1}{c}{ Method } & Condition & $\begin{array}{c}\text { Wilks } \\
\text { lambda }\end{array}$ & Significance \\
\hline $\begin{array}{l}\text { Antibiotic disk } \\
\text { diffusion }\end{array}$ & $\begin{array}{c}\text { Direct } \\
\text { calculation } \\
\text { Ratio- }\end{array}$ & 0.003 & 0.144 \\
transformation & 0.000 & 0.020 \\
Biolog & 0.2 5AWCD* & 0.001 & 0.067 \\
& 0.50 AWCD & 0.003 & 0.144 \\
& 0.75 AWCD & 0.035 & 0.440 \\
\hline
\end{tabular}

*Average well color development.

others that did around $40 \%$. Variation explained by the pairs of the first and second $\mathrm{PC}$ axes ranged 60 to $67 \%$.

\section{RDA ordination}

RDA ordination diagrams in Fig. 2 indicate relationships between the bacterial profiles and the soil environmental factors. Only the significant environmental factors at $\mathrm{p}=0.05$ were shown as arrows. No multicolinearity was detected among the environmental factors. The ADD method gave Fig. 2a, indicating available phosphorus as the most significant soil environmental factor related to the susceptibility profiles. In the ordination plane, the CF soil was differentiated from the DEF soil by relatively high phosphorus availability. Eigenvalues for the first and second axes were 0.703 and 0.067 , respectively. The Biolog method gave different RDA ordination diagrams at the AWCD values. For the 0.25 AWCD data set, available phosphorus was the significant environmental factor related to the soil microbial profiles (Fig. 2b). In the 0.25 AWCD diagram, replicates of the $\mathrm{CF}$ soil located with short distances among them, while the DEF replicates showed large variation of score on the second axis. Eigenvalues for the first and second ordination axes were 0.258 and $0.08 \mathrm{~L}$, respectively. The RDA ordination diagrams for AWCD values of 0.50 and 0.75 (Fig. 2c, d) were similar each other, and different from that for an AWCD value of 0.25. For both the data sets on AWCD values of 0.50 and 0.75 , the most significant environmental factor was $\mathrm{pH}$, and the $\mathrm{CF}$ replicates had broaden the variation among them along the second axes, while that for the DEF replicates decreased. Eigenvalues for the first and second axes were 0.328 and 0.083 for the data set on an AWCD value of 0.50 , and 0.385 and 0.073 for an AWCD value of 0.75 .

\section{DISCUSSION}

The CF soil was rich in EC and phosphorus, and had a high $\mathrm{pH}$ value, seemingly because of the alluvial history and/or the location near the sea (7). On the contrary, the DEF soil was
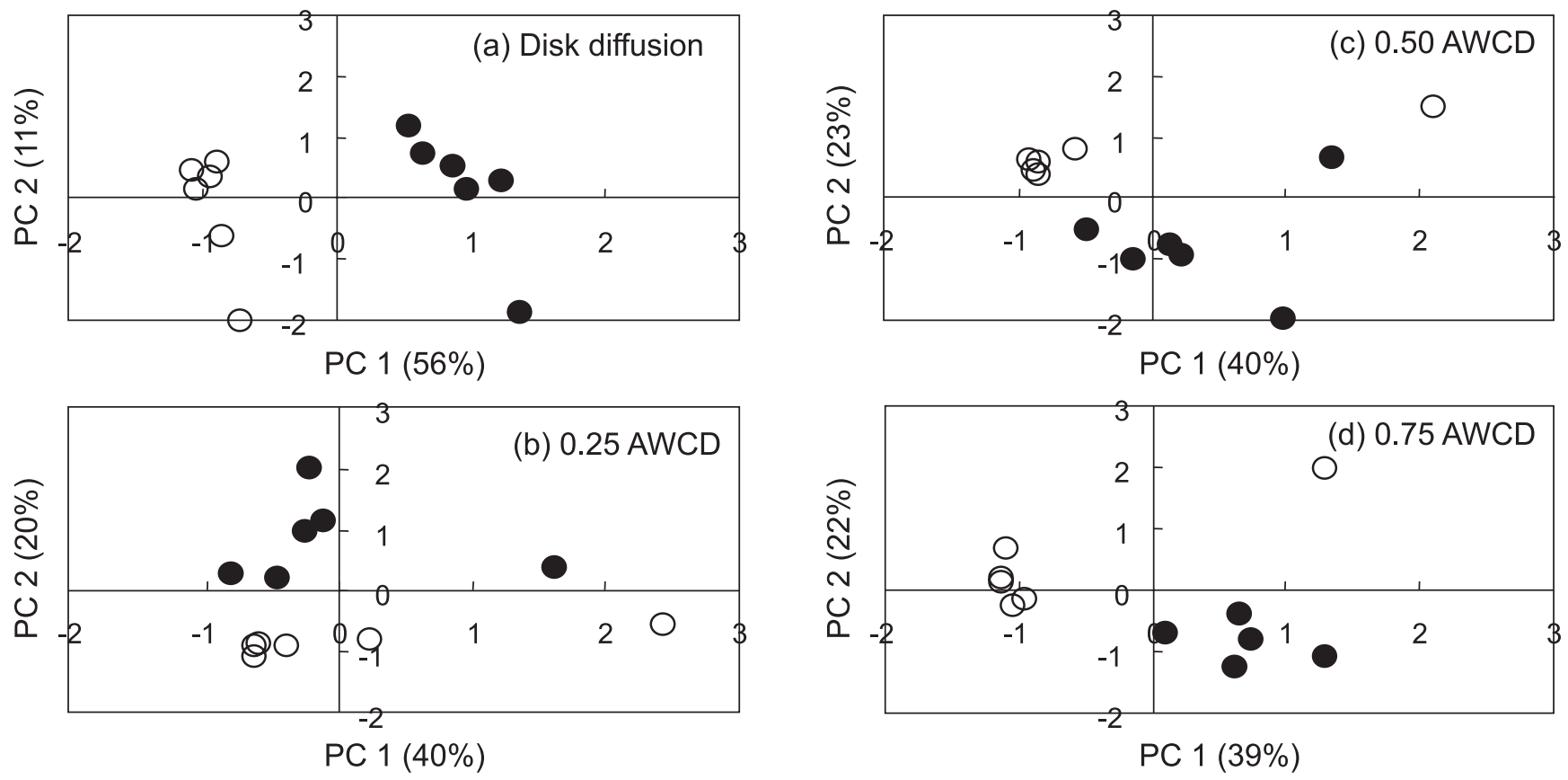

Figure 1. Principal component score plots for the methods and the AWCDs. The open and the solid symbols indicate DEF and CF, respectively. 

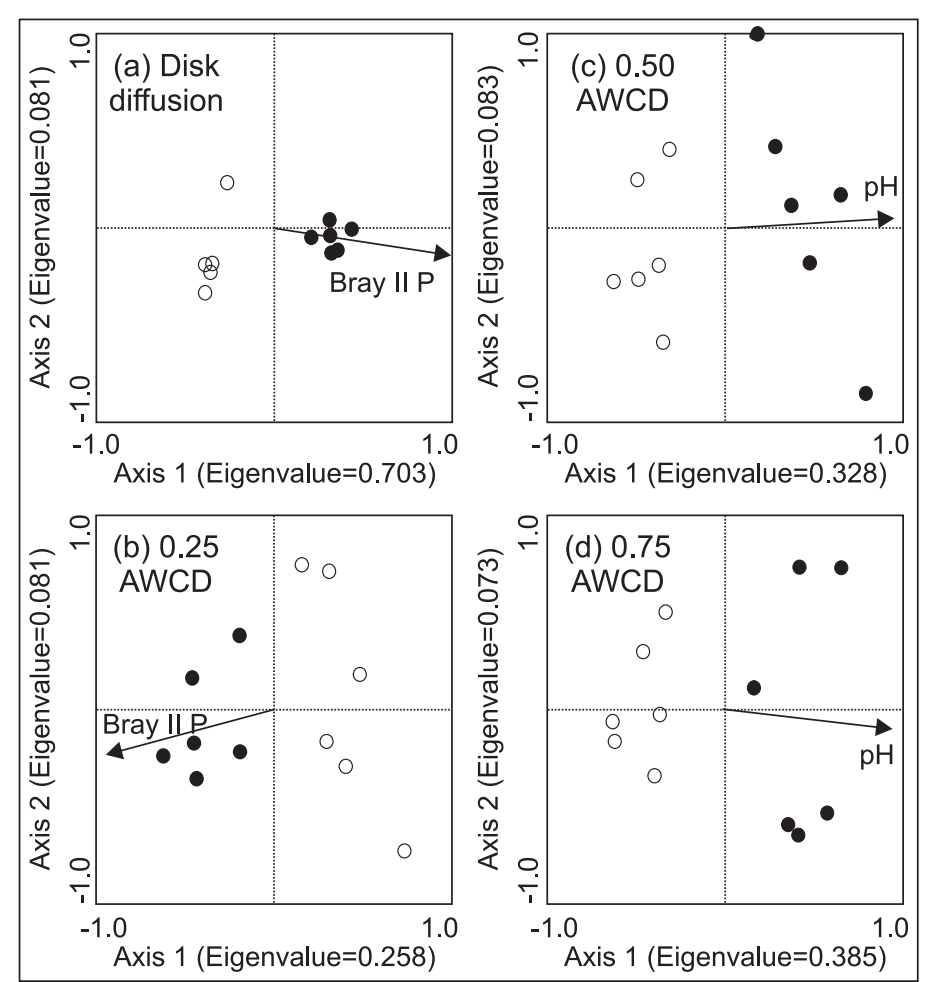

Figure 2. RDA ordination diagrams for the methods and the AWCDs. The open and the solid symbols indicate DEF and CF, respectively.

rich in carbon and nitrogen, possibly due to the continuous litter supply from the canopy. These differences had been expected to be reflected on differences between the bacterial community profiles.

Because of the diversity of the soil bacterial community inoculated, smear and/or duplicated arcs could occur. However, the arcs were clear. The selectivity of the medium must have decreased the original diversity and simplified the species composition of the bacterial communities (13). This is thought to contribute to the formation of the clear arcs. The purple coloration occurs when a substrate is oxidized, thus, the color development means that the physiological activity of the inoculated microbial community has occurred, while inside of the inhibitory circles, the physiological activity is inhibited. The physiological activity by soil bacteria and the inhibition were thought to be responsible for the purple color development and the inhibitory circle formation, because the antibiotics used in this research were antibacterials (1) and the medium included cycloheximide as a fungicide. This is a difference from the Biolog method, in which, bacteria as well as other microbes might have been responsible for the color development.

The results summarized in Table 2 suggest that the susceptibility patterns of the soil bacterial communities to the antibiotics were unique and distinctive. The improved discrimination of the soils by the ratio-transformation indicates that each pattern expressed as relative susceptibility of the bacterial community to the antibiotics was unique and independent from the viable cell number (Table 3).

Scoring a larger contribution rate of the first PC, the data set given by the ADD method was shown to be simpler than that by the Biolog method, perhaps due to the smaller number of variables. The PC score plot for the ADD method (Fig. 1a) better separated the sample groups than the Biolog method. This trend was also seen for the Wilk's lambda values (Table 3). The less successful discrimination in the PC score plots by the Biolog method could relate to the complexity of the Biolog data sets, i.e., PC score plots for the Biolog method separated the sample groups largely relying on scores on the second $\mathrm{PC}$ axis, which explained only 20 to $23 \%$ of the variation (Figs. 1b, c, d). On the other hand, separation of the sample groups was distinctive in relation to the environmental factors for all the data sets (Fig. 2). Each RDA diagram separated the sample groups along the first axis, and available phosphorus or $\mathrm{pH}$ well correlated to the first axis for the data sets on the ADD observations and an AWCD value of 0.25 or that on AWCD values of 0.50 and 0.75 , respectively. This indicates that the differences in available phosphorus and $\mathrm{pH}$ between the soils correlated linearly to some of the ADD or the Biolog variables (24). The larger eigenvalue for the first axis of the ADD diagram (Fig. 2a) is thought to associate with the clearer discrimination of the soils in the corresponding PC score plot (Fig. 1a) and the small Wilk's lambda value (Table 3 ). These pieces of information suggest that the differences in antibiotic susceptibility patterns (Table 2) were simpler and more distinctive than that in the Biolog color development patterns. This is also supported by the smaller variation of the scores on the first axis among each sample group as shown in Fig. 2a.

The ordination planes could be given by observing different aspects of soil microbial community. The Biolog method is based on the community level physiological function (27), and the other the susceptibility pattern. Thus, the ordination planes and the dimensions may be to some extent independent each other. The difference in pattern of PC score plot or RDA ordination diagram between the methods suggests the independence between the microbial aspects. On the other hand, any linkages between the aspects may have been involved. The color development in the Biolog method correlates to the number of cells in the well (17). An ADD profile of soil bacterial community relates to physiological activity of the bacterial cells inoculated. Thus, the methods tested in this research are based on and associate with bacterial cells. This factor may have led to incomplete independence between the dimensions of soil discrimination with these methods. The basal media used in the 
Biolog and the ADD methods may allow growth of taxonomically different microbial groups. This factor may, on the contrary, have increased the degree of independence between the dimensions of the discrimination.

Such independence among soil-related biotic aspects over the same spatial extent had been implied. Dimensions of discrimination of the same set of soils were implied to differ among data sets provided by Biolog, ester- and phospholipidlinked fatty acid profiling (22). Similar multidimensionality was also suggested for soil macro-invertebrate communities (15). In these instances, each community or aspect gave a unique ordination plane. Thus, each soil-related community may be more or less suitable for detecting the significant environmental gradient relating to a particular gradient such as occurrence of plant disease. The strategy taken by Bossio and Scow (3) is expected to find different sets of significant environmental gradients by analyzing various soil-related communities or biotic aspects.

In this trial, the ADD method showed the applicability to profiling and discrimination of soils, and determination of significant environmental factors that explain differences between antibiotic susceptibility profiles of soil bacterial communities. Though, the ADD method had a smaller number of variables than the Biolog method, most variables detected differences in susceptibility of the bacterial communities to the antibiotics (Table 2). The Biolog method has been reported to have many variables poorly contributing to discrimination of microbial communities (14). It is still difficult to determine effects of this factor on the Biolog method and soil discrimination. Therefore, the ADD method should further be examined before concluding the general applicability to more cases and the relative superiority over the Biolog method. The attractiveness of the ADD method is that the antibiotic susceptibility pattern may directly link to ecological facts about the microbial community (12). It seems to be meaningful to improve, examine and develop the ADD method, because it is cost effective, less labor-intensive, easy to perform and may reveal a uniquely informative dimension of soil discrimination.

\section{ACKNOWLEDGEMENTS}

I thank the Sasakawa Scientific Research Grant from the Japan Science Society for financial support. Prof. Dr. Pongsak Sahunalu, Dr. Chongrak Vatcharinratana and Mr. Sakhan Teejuntuk, Faculty of Forestry, Kasetsart University, Thailand helpfully provided support. Mr. Pramuk Kaeoniam and other staff members of the SERS assisted this work. Prof. Dr. Katsutoshi Sakurai, Faculty of Agriculture, Kochi University gave many pieces of advice and suggestions to power my performance. Mr. Jua Kuakit, the owner of the citrus field quite readily and powerfully helped the soil sampling. I gratefully acknowledge the support from these people.

\section{RESUMO}

\section{Aplicação do método de difusão de disco de antibiótico para traçar o perfil da comunidade bacteriana no solo: comparação de seu poder discriminatório e dimensão da discriminação em relação ao método Biolog}

O método de Difusão de Disco de Antibiótico (ADD) foi comparado ao método Biolog quanto ao seu poder de discriminar solos e quanto à dimensão da discriminação, analisando-se os solos de uma floresta e de um campo de cítricos na Tailândia. A diferenciação dos solos por esses métodos foi feita de acordo com o score plot do componente principal.Em seguida, determinou-se o valor de lambda de Wilk para estimar o poder discriminatório desses métodos. $\mathrm{O}$ método $\mathrm{ADD}$ resultou em lambda de Wilk de 0,003 ( $\mathrm{p}=0,144)$ e $0,035(\mathrm{p}=0,440)$ para os valores diretos e transformados, respectivamente. Enquanto o método Biolog resultou em valores de lambda de Wilk de 0,001 ( $\mathrm{p}=0,067), 0,003(\mathrm{p}=0,144)$ e $0,035(\mathrm{p}=0,440)$ para os valores médios de desenvolvimento de cor (AWCDs) 0,25 , 0,50 e 0,75 respectivamente, o método ADD apresentou poder discriminatório elevado, ou, no mínimo semelhante ao do método Biolog. A análise de redundância resultou em diagramas que revelaram uma diferença na dimensão da discriminação entre os métodos e os valores de AWCD. Os fatores ambientais do solo que estiveram significativamente relacionados com os perfis bacterianos $(\mathrm{p}=0,0)$ foram: fósforo disponível (método ADD e Biolog 0,25 AWCD) e pH (Biolog 0,50 e 0,75 AWCD). Esses resultados indicaram que os dois métodos e as AWCDs revelaram a multidimensionalidade da discriminação. A aplicação do método ADD para obtenção dessas informações para um gerenciamento eficiente do solo foi sugerida.

Palavras-chave: antibiótico, Biolog, difusão de disco, comunidade microbiana no solo.

\section{REFERENCES}

1. Acar, J.F.; Goldstein, F.W. Disk susceptibility test. In: Lorian, V. (eds). Antibiotics in laboratorymedicine. 4th ed. Williams and Wilkins, Baltimore, 1996, p.1-51.

2. Angle, J.S.; McGrath, S.P.; Chaney, R.L. New culture medium containing ionic concentrations of nutrients similar to that found in the soil solution. Appl. Environ. Microbiol., 57:3674-3676, 1991.

3. Bossio, D.A.; Scow, K.M. Impact of carbon and flooding on the metabolic diversity of microbial communities in soils. Appl. Environ. Microbiol., 61:4043-4050, 1995.

4. Brønstad, K.; Drønen, K.; Øvreås, L.; Torsvik, V. Phenotypic diversity and antibiotic resistance in soil bacterial communities. $J$. Indust. Microbiol., 17:253-259, 1996.

5. Bunyavejchewin, S. Ecological studies of tropical semi-evergreen rain forest at Sakaerat, Nakhon Ratchasima, northeast Thailand, I vegetation patterns. Nat. Hist. B. Siam Soc., 34:35-57, 1986.

6. Doyle, J.D.; Stotzky, G. Methods for the detection of changes in the microbial ecology of soil caused by the introduction of microorganisms. Microb. Release., 2:63-72, 1993. 
7. Edelman, C.H.; van der Voorde, P.K.J. Important characteristics of alluvial soils in the tropics. Soil Sci., 95:258-263, 1963.

8. FAO/UNESCO. Soil map of the world. IX, Southeast Asia. UNESCO, Paris. 1979

9. Francl, L.J. Multivariate analysis of selected edaphic factors and their relationship to Heterodera glycines population density. $J$. Nematol. 25:270-276, 1993.

10. Fujie, K.; Hu, H-Y.; Tanaka, H.; Urano, K.; Saitou, K.; Katayama, A. Analysis of respiratory quinones in soil for characterization of microbiota. Soil Sci. Plant Nutr., 44:393-404, 1998.

11. Garland, J.L.; Mills, A.L. Classification and characterization of heterotrophic microbial communities on the basis of patterns of community-level sole-carbon-source utilization. Appl. Environ. Microbiol., 57:2351-2359, 1991

12. Gottlieb, S. The production and role of antibiotics in soil. J. Antibiot., 29:987-1000, 1976.

13. Gray, T.R.G. Methods for studying the microbial ecology of soil. Meth. Microbiol., 22:309-341, 1990.

14. Haack, S.K.; Garchow, H.; Klug, M.J.; Forney, L.J. Analysis of factors affecting the accuracy, reproducibility, and interpretation of microbial community carbon source utilization patterns. Appl. Environ. Microbiol., 61:1458-1468, 1995.

15. Hemerik, L.; Brussaard, L. Diversity of soil macro-invertebrates in grasslands under restoration succession. Europ. J. Soil Biol., 38:145$150,2002$.

16. Kanzaki, M.; Yoda, K.; Dhanmanonda, K. Mosaic structure and tree growth pattern in a monodomoionant tropical seasonal evergreen forest in Thailand. In: Box, E. O.; Peet, R. K.; Masuzawa, T.; Yamada, I.; Fujiwara, K.; Maycosk, P. F. (eds). Vegetation science in forestry.Kluwer Publishers, Netherlands, 1995. p.495-513.

17. Lindstrom, J.E.; Barry, R.P. ; Braddock, J.F. Microbialcommunity diversity analysis: a kinetic approach to constructing potential C source utilization patterns. Soil Biol. Biochem., 30:231-239, 1998.
18. Lyon, J.; Sagers, C.L. Correspondence analysis of functional groups in a riparian landscape. Plant Ecol., 164:171-183, 2002.

19. MacMillan, D.C. Predicting the general yield class of Sitka spruce on better quality land in Scotland. Forestry, 64:359-372, 1991.

20. Mausbach, M.J.; Seybold, C.A. Assessment of soil quality. In: Lal, R. (eds). Soil quality and agricultural sustainability. Ann Arbor Press, Chelsea, Michigan. 1998. p.33-43.

21. Pankhurst C.E.; Doube, B.M.; Gupta, V.V.S.R. Biological indicators of soil health, CAB International, Wallingford, UK, 1997, 451p.

22. Pankhurst C.E.; Yu, S.; Hawke, B.G.; Harch, B.D. Capacity of fatty acid profiles and substrate utilization patterns to describe differences in soil microbial communities associated with increased salinity or alkalinity at three locations in South Australia. Biol. Fertil. Soil, 33:201-217, 2001

23. Sena, M.M.; Poppi, R.J.; Frighetto, R.T.S.; Valarini, P.J. Avaliação do uso de métodos quimiométricos em análise de solos. Quím. Nova, 23:547-556, 2000

24. ter Braak, C.J.F.; Šmilauer, P. Canoco reference manual and user's guide to Canoco for windows: software for canonical community ordination (vesion 4), Microcomputer Power, Ithaca, NY, 1998, $352 \mathrm{p}$.

25. Tunlid, A.; White, D.C. Biochemical analysis of biomass, community structure, nutritional status and metabolic activity of microbial communities in soil. In: Stotzky G.; Bollag, J.-M. (eds). Soil Biochemistry Vol. 7, Marcel Dekker, New York, 1992, p.229262.

26. Webster, R. Statistics to support soil research and their presentation. Europ. J. Soil Sci., 52:331-340, 2001.

27. Zak J.C.; Willing M.R.; Moorhead D.L.; Wildman H.G. Functional diversity of microbial communities: a quantitative approach. Soil Biology and Biochemistry, 26:1101-1108, 1994

28. Zar, J.H. Biostatistical analysis, Prentice-Hall, New Jersey, 1999, $718 \mathrm{p}$. 